\title{
Antihyperglycemic Activity of Moringa oleifera Lam Leaf Functional Tea in Rat Models and Human Subjects
}

\author{
Edith N. Fombang*, Romuald Willy Saa \\ Department of Food Science and Nutrition, National School of Agro-Industrial Sciences (ENSAI), University of Ngaoundere, \\ Ngaoundere, Cameroon \\ Email: ^edfombang@yahoo.fr
}

How to cite this paper: Fombang, E.N. and Saa, R.W. (2016) Antihyperglycemic Activity of Moringa oleifera Lam Leaf Functional Tea in Rat Models and Human Subjects. Food and Nutrition Sciences, 7, 1021-1032. http://dx.doi.org/10.4236/fns.2016.711099

Received: August 20, 2016

Accepted: September 20, 2016

Published: September 23, 2016

Copyright $\odot 2016$ by authors and Scientific Research Publishing Inc. This work is licensed under the Creative Commons Attribution International License (CC BY 4.0).

http://creativecommons.org/licenses/by/4.0/ (c) (i) Open Access

\section{Abstract}

Maintenance of glycemic control is important in preventing diabetes and its associated complications. Considering the current recommended approach for the use of functional foods and their bioactive components in the prevention and management of diabetes, the aim of this study was to determine the antihyperglycemic effect of Moringa oleifera functional tea in rat models and in normoglycemic human volunteers using the oral glucose tolerance test (OGTT). Moringa tea prepared by extracting Moringa leaf powder in distilled water $(1: 20 \mathrm{mg} / \mathrm{ml})$ at $97^{\circ} \mathrm{C}$ for $30 \mathrm{~min}$ was administered at different doses to male Wistar rats and human volunteers prior to glucose loading. Blood glucose was measured at intervals of $30 \mathrm{~min}$ for $150 \mathrm{~min}$. Consumption of Moringa tea prior to glucose loading suppressed the elevation in blood glucose in all cases compared to controls that did not receive the tea initially. The degree and pattern of decrease however, were dose dependent. In rats, intermediate doses of $20 \mathrm{ml} / \mathrm{kg}$ BW were more effective in reducing blood glucose overall (18.2\%) vs $13.3 \%$ and $6 \%$ at doses of 10 and $30 \mathrm{ml} / \mathrm{kg} \mathrm{BW}$ respectively. In humans, the final decrease in blood glucose was not significantly different for high $400 \mathrm{ml}$ (19\%) and low $200 \mathrm{ml}(17 \%)$ doses. Of interest here was the pattern of decrease, being significantly higher $(\mathrm{p}<0.05)$ at $30 \mathrm{~min}$ with $200 \mathrm{ml}(22.8 \%)$ than with $400 \mathrm{ml}(17.9 \%)$. It is suggested that low doses exert their antihyperglycemic effect more at intestinal level by inhibiting glucose absorption, whereas high doses exert their effect more in circulation. We conclude that Moringa oleifera tea has potential as a functional food in the management of hyperglycemia.

\section{Keywords}

Moringa oleifera Functional Tea, Antihyperglycemic Activity, Phenolic Compounds, Antioxidant Activity, Humans, Rats 


\section{Introduction}

Diabetes is a metabolic disorder characterized by a dysfunction of carbohydrate metabolism resulting in hyperglycemia [1]. Worldwide, 415 million people were estimated to have diabetes in 2015, with this number projected to increase to 642 million in 2040 [2]. These figures translate in one in eleven adults having diabetes. Three quarters of these persons live in low and middle income countries, and diabetes was responsible for five million deaths in 2015 alone [2]. Maintenance of glucose homeostasis is of utmost importance to human physiology. Failure to maintain this control can result in metabolic syndrome, a multi symptom disorder of energy homeostasis encompassing obesity, hyperglycemia, impaired glucose tolerance, hypertension and dyslipidemia [3]. Insulin resistance is the most characteristic abnormality present in metabolic syndrome. It results from interactions between genetic and environmental factors, including diet and a sedentary lifestyle [3]. Metabolic syndrome is the major predisposing factor for type 2 diabetes, where defects in both insulin action and insulin secretion are present.

Among the multiple risk factors associated with the incidence and progression of type 2 diabetes, diet is the main modifiable factor. As reviewed by Bahadoran et al. [4], several epidemiological investigations have shown that diets rich in foods with high content of phytochemicals and high antioxidant capacity may be related to lower risk of diabetes and its predisposing factors. Dietary plant polyphenols and polyphenol-rich products modulate carbohydrate and lipid metabolism, attenuate hyperglycemia, dyslipidemia and insulin resistance [3] [5] [6]. In addition, polyphenols are safe and present no side-effects. Recently the use of functional foods and their bioactive components have been considered as a new approach in the prevention and management of diabetes and its complications [4]. Polyphenols, due to their biological properties, may be appropriate nutraceuticals and supplementary treatments for diabetes mellitus.

Moringa oleifera is a plant used in the management of type 2 diabetes and belongs to the Moringaceae family. Water and ethanol extracts of its leaves have been shown to possess hypoglycemic, antihyperglycemic and antidiabetic activity in normoglycemic and in diabetic rats [5]-[8]. These have mostly been used in the powder form and with animal models. Its anti-diabetic activity may be attributed to phenolic compounds such as flavonoids, phenolic acids, and tannins which have been reported to have antihyperglycemic activity [3] [9] [10]. Previously, optimal conditions for the production of a phytochemical-rich, antioxidant Moringa oleifera leaf functional tea were determined [11]. This tea is rich in polyphenols, has antioxidant and reducing capacity similar to DPPH and ascorbic acid respectively. With the recent interest in functional foods for the control of blood glucose, the present study investigates the potential of this tea in regulating blood glucose levels in human subjects and in rat models.

\section{Materials and Methods}

\subsection{Plant Material and Preparation of Flour}

Moringa oleifera leaves were harvested in Maroua in the Far North Region of Cameroon and transported to the Food Biophysics, Biochemistry and Nutrition Laboratory, 
of the National School of Agro-Industrial Sciences (ENSAI) of the University of Ngaoundere. Leaflets were detached from the Moringa oleifera leaves, sorted to remove dead leaves, washed with distilled water, rinsed and drained on plastic trays for $30 \mathrm{mi}$ nutes before drying at $45^{\circ} \mathrm{C} \pm 2{ }^{\circ} \mathrm{C}$ for $14 \mathrm{~h}$ in a ventilated electric dryer (Riviera \& Bar QD105A, Paris, France). Dried leaves were ground in a mill (Culatti, Polymix, France) and sieved through a $500 \mu \mathrm{m}$ sieve to obtain powder. The powder samples were stored in airtight glass jars at $4^{\circ} \mathrm{C}$.

\subsection{Preparation of Moringa oleifera Functional Tea}

Using previously established optimal conditions [11], Moringa oleifera functional tea was prepared by extracting Moringa leaf powder in distilled water at a ratio of 1:20 $\mathrm{g} / \mathrm{ml}$, at $97^{\circ} \mathrm{C}$ for $35 \mathrm{~min}$, and filtered using Whatman filter paper.

\subsection{Characterization of M. oleifera Functional Tea}

\subsubsection{Determination of Phytochemical Content}

1) Total polyphenols

The total polyphenols were determined by the method of [12]. Extract (10 $\mu \mathrm{l})$ was diluted 20 times with distilled water $(2.99 \mathrm{ml})$ in a test tube and mixed with $500 \mu \mathrm{l}$ of Folin-Ciocalteu reagent and $400 \mu \mathrm{l}$ of $7.5 \%$ sodium carbonate (w/v). The mixture was votexed, and incubated in the dark at room temperature for ten minutes. The absorbance was measured at $760 \mathrm{~nm}$ using a spectrophotometer (Metertech SP8001, Germany). Total phenolic content was calculated against a calibration curve established using gallic acid and expressed as mg gallic acid equivalent (GAE) per $100 \mathrm{ml}$.

2) Total flavonoids

Total flavonoids were determined by a colorimetric method as described by [13]. To $0.1 \mathrm{ml}$ of extract was added $2.4 \mathrm{ml}$ of distilled water and $0.15 \mathrm{ml}$ of sodium nitrite (5\% $\mathrm{w} / \mathrm{v}$ ) and the mixture incubated at $25^{\circ} \mathrm{C}$ for 5 mins. Thereafter, $0.15 \mathrm{ml}$ of Aluminum chloride hexahydrate $(10 \% \mathrm{w} / \mathrm{v})$ was added followed by a second incubation. Finally 1 $\mathrm{ml}$ of $1 \mathrm{M}$ sodium hydroxide solution was added and the optical density was read at 510 $\mathrm{nm}$ against a reagent blank. A calibration curve was established using catechin solution. Flavonoid concentration was calculated from the calibration curve and expressed as catechin equivalents per $100 \mathrm{ml}$.

3) Total tannins

Total tannins were determined using the vanillin $\mathrm{HCl}$ method [14]. To $1 \mathrm{ml}$ of extract was added $3 \mathrm{ml}$ of $4 \%(\mathrm{w} / \mathrm{v})$ vanillin in methanol, followed by addition of $1.5 \mathrm{ml}$ concentrated hydrochloric acid. The mixture was vortexed and incubated at $30^{\circ} \mathrm{C}$ for 20 min. The absorbance was read at $500 \mathrm{~nm}$ against a blank. Tannin content was calculated from a standard curve prepared using tannic acid solution $(0.2 \mathrm{~g} / \mathrm{L})$. The results were expressed as equivalent grams of tannic acid per $100 \mathrm{ml}$.

\subsubsection{Determination of Antioxidant Activity}

1) $\mathrm{DPPH}$ radical scavenging activity

Antioxidant capacity (Radical scavenging activity) of $M$. oleifera functional tea was 
determined using the modified Brand-Williams et al. [15] method. DPPH (2,2'-diphenyl-1-picryl hydrazyl) in ethanol is a stable radical, dark violet in color. Its color is bleached by its reaction with a hydrogen donor. For analyses, $0.1 \mathrm{ml}$ of $M$. oleifera tea was added to $2 \mathrm{ml}$ of $100 \mu \mathrm{M}$ DPPH solution in ethanol. Ethanol without extract was included as control. The reaction mixture was incubated for $30 \mathrm{~min}$ in the dark at $25^{\circ} \mathrm{C}$ and the absorbance read at $517 \mathrm{~nm}$. Vitamin $\mathrm{C}$ was used as the standard against which the antioxidant activity of the tea was compared. The free radical scavenging activity was calculated as follows:

$$
\text { DPPH Radical Scavenging Activity }(\%)=\frac{(\text { Abs.control }- \text { Abs.extract }) * 100}{\text { Abs.control }}
$$

where Abs. is the Absorbance at $517 \mathrm{~nm}$.

DPPH activity was expressed as \% inhibition.

2) Total reducing power

The reducing power of $M$. oleifera functional tea was determined by the method of [16] using potassium ferricyanide $\left(\mathrm{K}_{3} \mathrm{Fe}(\mathrm{CN})_{6}\right)$. An aliquot of extract $(100 \mu \mathrm{l})$ was mixed with equal amounts of $0.2 \mathrm{M}$ phosphate buffer ( $\mathrm{pH}$ 6.6) and $1 \%$ potassium ferricyanide and incubated for $20 \mathrm{~min}$ at $50^{\circ} \mathrm{C}$ followed by precipitation with $10 \% \mathrm{TCA}$. After centrifugation at $3500 \mathrm{rpm}$ for 15 minutes, the supernatant was diluted with equal volumes of distilled water and $100 \mu \mathrm{l}$ of $0.1 \%$ ferric chloride $\left(\mathrm{FeCl}_{3}\right)$ to determine ferric reducing capacity of Moringa tea. The absorbance was read at $700 \mathrm{~nm}$ against a reagent blank. A higher absorbance indicates a higher reducing power because more ferric cyanide is reduced to ferrous cyanide by the tea. Ascorbic acid was used as reference standard and results expressed as ascorbic acid equivalence (g AAE/100g Dry Matter DM).

3) Ferrous ion chelating power

Ferrous ion chelating power was determined using the method of Suter and Richter [17] with slight modification. Reagent solution $(100 \mu \mathrm{l}$ of ferrous chloride $(2 \mathrm{mM})+$ $400 \mu$ l of potassium ferro cyanide $5 \mathrm{mM}$ ) was mixed with $200 \mu \mathrm{l}$ of Moringa tea and 1 $\mathrm{mL}$ of distilled water. The mixture was incubated at $20^{\circ} \mathrm{C}$ for $10 \mathrm{~min}$ and the absorbance read at $700 \mathrm{~nm}$ using a spectrophotometer (Metertech SP8001, Germany). EDTA standard was used as a positive control. Ferrous ion chelating power CP was calculated using the formula:

$$
C P(\%)=\frac{A_{\text {control }}-A_{\text {tea }}}{A_{\text {control }}} \times 100
$$

\subsection{Antihyperglycemic Activity of Moringa oleifera Functional Tea}

The antihyperglycemic activity of Moringa oleifera functional tea was determined in rat models and in human subjects using the oral glucose tolerance test (OGTT). The ability of Moringa tea to complex free glucose in solution was also determined.

\subsubsection{Antihyperglycemic Activity in Rat Models}

Twenty five male Wistar albino rats, weighing between 250 and $378 \mathrm{~g}$ were obtained from the animal laboratory of the Faculty of Science of the University of Ngaoundere. 
The animals were housed individually in semi-metabolic cages in the animal house of the National School of Agro-industrial Sciences (ENSAI), at an average temperature of $25^{\circ} \mathrm{C} \pm 2{ }^{\circ} \mathrm{C}$ and a relative humidity of $60 \%-70 \%$ with $12 / 12 \mathrm{~h}$ cycles of light and darkness. Rats were allowed to acclimatize for one week on a standard rat diet. The animals had free access to food and water during this period.

At the end of the acclimatization period, the rats were randomly assigned into 5 groups of 5 animals each for the antihyperglycemic experiments. The groups comprised a negative (G1) and a positive (G2) control group, with 3 experimental (G3, G4, G5) groups. To determine the antihyperglycemic activity of Moringa oleifera functional tea, rats were fasted overnight for $12 \mathrm{~h}$. After the overnight fast, blood was withdrawn from the animal's tail vein and fasting blood glucose measured using a glucometer (OneTouch Ultra 2, LifeScan, Inc.) [18]. Thereafter, animals in the control groups (G1, G2) were gavaged with distilled water at doses of $20 \mathrm{ml} / \mathrm{kg}$ body weight (BW), while animals in the 3 treatment groups (G3, G4, G5) were gavaged with Moringa tea at doses of 10 , 20 and $30 \mathrm{ml} / \mathrm{kg} \mathrm{BW}$ respectively. Thirty minutes later, glucose overload was given to the animals in the positive control group G2 and the 3 treatment group by gavage at a dose of $4 \mathrm{~g} / \mathrm{kg}$ BW. The negative control group G1 was given distilled water. Blood glucose level was measured at intervals of $30 \mathrm{~min}$ for the next $150 \mathrm{~min}$ following glucose administration. Animals were treated in accordance with the guidelines for animal experimentation of the University of Ngaoundere [19].

\subsubsection{Antihyperglycemic Activity in Human Subjects}

To determine antihyperglycemic activity of Moringa tea in humans, the effect of a single ingestion of Moringa tea on postprandial blood glucose elevation in normal subjects was evaluated. Fifteen normoglycemic male volunteers aged 20 to 29 years, all student of the University of Ngaoundere, participated in the study. The students weighed between 60 and $80 \mathrm{~kg}$, with height ranging from 1.72 to $1.83 \mathrm{~m}$, and an average BMI of $21.6 \pm 1.7 \mathrm{Kg} / \mathrm{m}^{2}$. Fasting blood glucose of the subjects taken twice and for 2 days consecutively ranged between 70 and $98 \mathrm{mg} / \mathrm{dl}$ with a mean of $86.2 \pm 8.4 \mathrm{mg} / \mathrm{dl}$. The subjects were thus non-diabetic as their fasting blood glucose level was below the pathological level of $>126 \mathrm{mg} / \mathrm{dl}$ [1]. Prior to taking part in the study, its purpose was explained to the participants and their informed consent obtained. The study protocol was approved by the ethics committee of the University of Ngaoundere.

The fifteen volunteers were randomly assigned into 3 groups of five persons each. The 3 groups consisted of a control group and 2 treatment groups. All the subjects were fasted overnight for $12 \mathrm{~h}$, after which their blood glucose level was measured in blood obtained by the finger-prick method using a glucometer (OneTouch Ultra 2, LifeScan, Inc.). The subjects were then given $200 \mathrm{ml}$ ( 1 cup) and $400 \mathrm{ml}$ ( 2 cups) of Moringa tea for the treatment groups $\mathrm{T} 1$ and $\mathrm{T} 2$ respectively, while the control group received 200 $\mathrm{ml}$ distilled water. The tea and water was consumed within $5 \mathrm{~min}$. This was followed 30 min later by the administration of $50 \mathrm{~g}$ of glucose (Munro Glucose-D) in $200 \mathrm{ml}$ of distilled water, for all the three groups. Blood glucose was then measured at intervals of 30 min for the next $150 \mathrm{~min}$. Duplicate measurements were taken per subject. 


\subsection{Complexation of Glucose by Moringa Tea}

This test estimates the capacity of Moringa tea to complex free glucose in vitro. For this, $10 \mathrm{ml}$ of a glucose solution $(0.61 \mathrm{~g} / \mathrm{l})$ was mixed with $10 \mathrm{ml}$ of Moringa tea. For the control sample, $10 \mathrm{ml}$ of glucose solution was mixed with $10 \mathrm{ml}$ of distilled water. The resulting mixture was incubated at $37^{\circ} \mathrm{C}$ for $15 \mathrm{~min}$ [18]. Unbound glucose remaining in solution after this time was measured using the method of [19].

\subsection{Expression of Results and Statistical Analysis}

Percentage reduction in blood sugar was calculated as the difference in blood glucose at time $t$ between the treatment group and the control group. Total reduction in blood glucose was calculated as proposed by [20].

Results are presented as means $\pm \mathrm{SD}$, and means were separated using the Duncan Multiple Range Test at the 5\% level with the software Stat-graphic centurion 15.2 (StatPoint Technologies, Inc, Warrenton, Virginia, USA). Graphs of changes in blood glucose level with time were plotted using Sigma Plot version 11.

\section{Results}

\subsection{Phytochemical Content and Antioxidant Capacity of M. oleifera Functional Tea}

Phenolic compounds content and antioxidant capacity of $M$. oleifera functional tea are presented on Table 1. Moringa tea contains respectively 56.96, 34.66 and $3.53 \mathrm{mg} / 100$ $\mathrm{ml}$ of total polyphenols, flavonoids and tannins. It equally possesses significant antioxidant capacity with radical scavenging activity (81\%), a chelating power of $85 \%$ and total reducing power of $1.75 \mathrm{~g}$ Ascorbic Acid Equivalent/100g DM.

\subsection{Test of Glycosylation or Glucose Complexing}

The glycosylation test gives the amount of glucose complexed by the tea and thus unavailable for digestion and or absorption. Addition of $M$. oleifera tea to glucose solution reduced the amount of glucose detectable in solution by $36.57 \%$.

Table 1. Phytochemical contents and antioxidant capacity of $M$. oleifera functional tea.

\begin{tabular}{ll}
\hline Component & Quantities \\
\hline Phytochemical content & \\
Total polyphenols $(\mathrm{mg} / 100 \mathrm{ml})$ & $56.96 \pm 0.75$ \\
Total flavonoids $(\mathrm{mg} / 100 \mathrm{ml})$ & $34.66 \pm 0.72$ \\
Total tannins $(\mathrm{mg} / 100 \mathrm{ml})$ & $3.53 \pm 0.03$ \\
Antioxidant capacity & \\
DPPH scavenging activity (\% inhibition) & $80.94 \% \pm 0.76 \%$ \\
Chelating power (\% inhibition) & $85.26 \% \pm 10.9 \%$ \\
Total reducing power (g AAE/100g DM) & $1.75 \pm 0.21$ \\
\hline
\end{tabular}

AAE: Ascorbic acid equivalence. 


\subsection{Antihyperglycemic Effect of M. oleifera Functional Tea on Blood Glucose in Rat Models}

The effect of different doses of $M$. oleifera tea on blood glucose levels in rats is shown in Figure 1 and Table 2. All the animals had similar fasting blood glucose, but that of the negative control group (G1) that received only distilled water remained stable $(64.0 \pm$ $4.5 \mathrm{mg} / \mathrm{dl}$ ) throughout the experimental period. Glucose ingestion resulted in an increase in blood glucose levels. Consumption of Moringa tea prior to glucose overload did not bring about any significant reduction in blood glucose levels for up to $60 \mathrm{~min}$ in group G4 and up to $90 \mathrm{~min}$ in groups G3 and G5. Beyond these times, blood glucose dropped significantly $(\mathrm{p}<0.05)$ in the treatment groups compared to G2 (Figure 1).

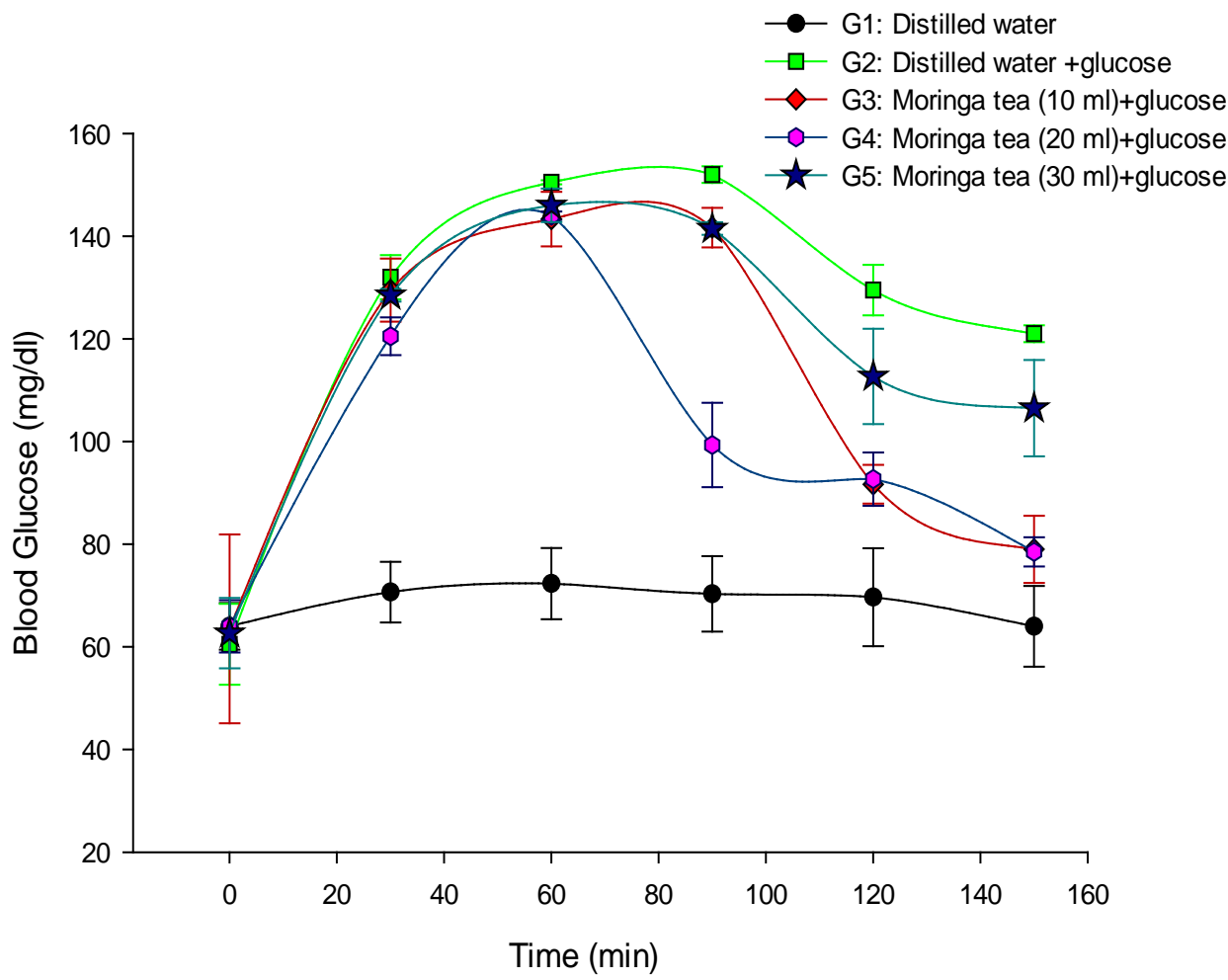

Figure 1. Effects of Moringa oleifera tea on blood glucose level of experimental rats. Tea (ml/kg $\mathrm{BW})$; glucose (4 g/kg BW).

Table 2. Percentage reduction of glycaemia at different doses of administration of Moringa oleifera tea in rats.

\begin{tabular}{ccccccc}
\hline \multirow{2}{*}{ Groups } & \multicolumn{5}{c}{ Percentage (\%) reduction in glycaemia } & \% total \\
\cline { 2 - 6 } & $30 \mathrm{~min}$ & $60 \mathrm{~min}$ & $90 \mathrm{~min}$ & $120 \mathrm{~min}$ & $150 \mathrm{~min}$ & Reduction \\
\hline G3: $10 \mathrm{ml} / \mathrm{Kg} \mathrm{BW}$ & 1.89 & 4.78 & 6.78 & 29.30 & 34.71 & 13.25 \\
G4: $20 \mathrm{ml} / \mathrm{Kg} \mathrm{BW}$ & 8.71 & 4.32 & 34.67 & 28.42 & 35.12 & 18.21 \\
G5: $30 \mathrm{ml} / \mathrm{Kg} \mathrm{BW}$ & 2.65 & 2.99 & 6.91 & 12.97 & 11.98 & 6.01 \\
\hline
\end{tabular}

G3: Moringa tea $(10 \mathrm{ml} / \mathrm{kg} \mathrm{BW})+$ glucose $4 \mathrm{~g} / \mathrm{kg}$ BW; G4: Moringa tea $(20 \mathrm{ml} / \mathrm{kg} \mathrm{BW})+$ glucose $4 \mathrm{~g} / \mathrm{kg}$ BW; G5: Moringa tea $(30 \mathrm{ml} / \mathrm{kg} \mathrm{BW})+$ glucose $4 \mathrm{~g} / \mathrm{kg} \mathrm{BW}$. 
Although G3 had a latent antihyperglycemic effect (after $90 \mathrm{~min}$ ) compared to G4 (after $60 \mathrm{~min}$ ), final glucose levels in both groups were comparable at $120 \mathrm{~min}$ (91.7 and 92.7 $\mathrm{mg} / \mathrm{dl}$ respectively) and at $150 \mathrm{~min}(79$ and $78.5 \mathrm{mg} / \mathrm{dl}$ respectively). Group G5 had higher glucose levels at $120(112.7 \mathrm{mg} / \mathrm{dl})$ and $150(106.5 \mathrm{mg} / \mathrm{dl}) \mathrm{min}$ in comparison. At 150 min, Moringa tea suppressed glucose elevation by $34.71 \%, 35.12 \%$ and $11.98 \%$ respectively at doses of 10 (G3), 20 (G4) and 30 (G5) ml/kg BW (Table 2). Lower doses were thus more effective in preventing hyperglycemia.

\subsection{Antihyperglycemic Effects of M. oleifera Funtional Tea on Blood Sugar Levels of Normal Human Subjects}

In humans, consumption of glucose alone (control group) significantly raised blood glucose levels which peaked after $30 \mathrm{~min}$ and thereafter decreased steadily down to 109 $\mathrm{mg} / \mathrm{dl}$ at $150 \mathrm{~min}$ (Figure 2). The consumption of Moringa tea before glucose administration, irrespective of dose attenuated the rise in postprandial blood glucose observed in the control group. However, the behavior of postprandial glucose with time was dose dependent. Lower dose of Moringa tea $200 \mathrm{ml}$ (T1) was more effective (22.8\%) in preventing the rise in blood glucose than higher dose (17.9\%) $400 \mathrm{ml}$ (T2), $30 \mathrm{~min}$ following glucose overload (Figure 2 and Table 3 ). Beyond this time, blood glucose of subjects in group T1 remained constant up to 90 min before dropping down to $88.3 \pm 8.0$ $\mathrm{mg} / \mathrm{dl}$ at $120 \mathrm{~min}$. After the initial rise in blood glucose at $30 \mathrm{~min}$ with a higher dose of tea (T2), there was a linear drop in glucose level down to $91.5 \pm 6.6 \mathrm{mg} / \mathrm{dl}$ at $120 \mathrm{~min}$ (Figure 2). In spite of their different trends, final blood glucose concentration at 150 min was comparable in both treatment groups $(88.5$ and $84 \mathrm{mg} / \mathrm{dl}$ respectively for groups T1 and T2), and was significantly $(\mathrm{p}<0.05)$ lower that of the control group $(109.3 \mathrm{mg} / \mathrm{dl})$.

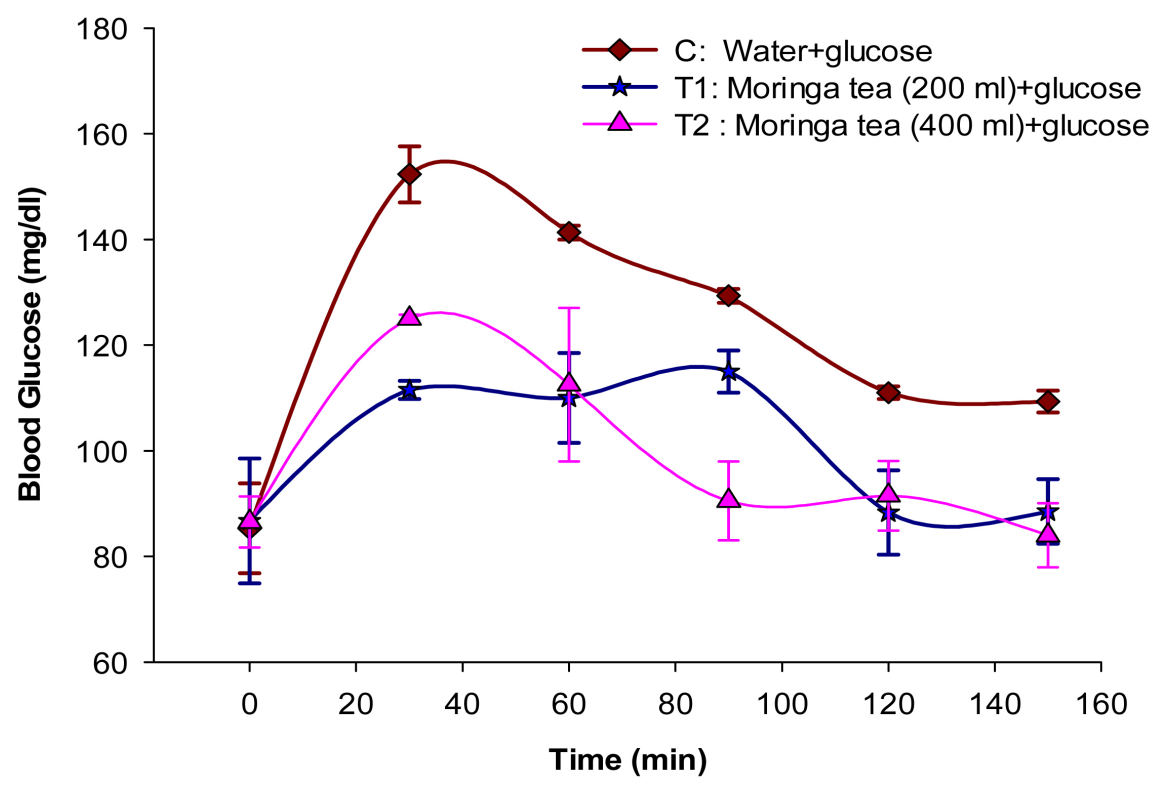

Figure 2. Effect of Moringa oleifera tea on blood glucose level of human subjects. 
Table 3. Percentage reduction in glycaemia at different doses of administration of Moringa oleifera tea in humans.

\begin{tabular}{ccccccc}
\hline \multirow{2}{*}{ Groups } & \multicolumn{5}{c}{ Percentage (\%) reduction in glycaemia } & \% total \\
\cline { 2 - 6 } & $30 \mathrm{~min}$ & $60 \mathrm{~min}$ & $90 \mathrm{~min}$ & $120 \mathrm{~min}$ & $150 \mathrm{~min}$ & Reduction \\
\hline T1: $200 \mathrm{ml}$ tea & 22.79 & 22.15 & 10.60 & 20.45 & 19.03 & 16.93 \\
T2: $400 \mathrm{ml}$ tea & 17.93 & 20.38 & 29.95 & 17.57 & 23.15 & 19.05 \\
\hline
\end{tabular}

T1: $200 \mathrm{ml}$ Moringa tea $+50 \mathrm{~g}$ glucose; T2: $400 \mathrm{ml}$ Moringa tea $+50 \mathrm{~g}$ glucose.

\section{Discussion}

Phenolic compounds are bioactive compounds with antioxidant potential, hypoglycemic, hypolipidemic and anti-tumor properties [21] [22]. Moringa oleifera functional tea contains polyphenols, flavonoids and tannins, making it a source of phenolic compounds. Dietary intake of polyphenols is estimated at $1 \mathrm{~g}$ per day [4]. Therefore a cup of Moringa tea $(200 \mathrm{ml})$, with $111.2 \mathrm{mg}$ polyphenols supplies one tenth of daily needs, whereas two cups $(400 \mathrm{ml})$ will supply one fifth of daily requirements.

In this study we demonstrate the antihyperglycmic activity of Moringa oleifera functional tea in rat models and in human subjects. In rat models the antihyperglycemic effect was more pronounced $90 \mathrm{~min}$ after glucose loading and more so at doses of 20 $\mathrm{ml} / \mathrm{kg}$ BW which impaired blood glucose rise by $34.67 \%$ vs $6.78 \%$ and $6.91 \%$ for low G3 (10 ml/kg BW) and high G5 (30 ml/kg BW) doses respectively. As evident from final blood glucose levels at the end of the experiment (Figure 1, Table 2), high dose G5 was least effective in reducing glycemia. The reason for this is not clear. However, the fact that increase in glycemia was not substantially reduced $60 \mathrm{~min}$ after the administration of glucose, may point to the fact that the mechanisms for glucose control intervene more at the level of circulation than at intestinal level. Recent work by [6] showed that normal and diabetic rats feed low and high doses (200 and $400 \mathrm{mg} / \mathrm{kg} / \mathrm{BW} /$ day) of powders from Moringa oleifera leaf aqueous extracts for 30 days, showed better glycemic control and an improvement in pancreatic cell and in insulin production especially in diabetic rats. Previous work by [8] reported better glucose tolerance (25.99\%, $31.25 \%$ and $43.19 \%$ ) in normal mice fed powders of Moringa leaf aqueous extracts at doses of 100, 200 and $300 \mathrm{mg} / 100 \mathrm{~g} \mathrm{BW}$ ). These results agree with ours; but their antihyperglycemic effect is achieved with higher doses compared to our study. This suggests that Moringa tea maybe a better and convenient form of consumption of Moringa for more efficient glycemic control.

In humans on the other hand, the antihyperglycemic effect was rapid, decreasing blood glucose by $22.8 \%$ and $17.9 \%, 30$ min after glucose loading with doses of 200 and $400 \mathrm{ml}$ respectively. Although a high dose of Moringa tea was less effective initially in preventing the rise in blood glucose, it achieved a greater reduction in glucose levels at 90 min compared to low dose T1. The greater reduction observed at $30 \mathrm{~min}$ with low doses of tea T1, coupled with the stable glucose levels up to $90 \mathrm{~min}$ (Figure 1), suggests that the effect of this dose was more important at the intestinal level possibly through inhibition of glucose uptake. Our results of $36.57 \%$ reduction in free glucose in solution 
following incubation with Moringa tea supports this assertion, as it would appear that Moringa tea binds glucose. Higher doses appear to exhibit their antihyperglycemic activity more in circulation than at the intestinal level considering their slower effect in preventing blood glucose increase at $30 \mathrm{~min}$ and the rapid drop in blood glucose thereafter.

Aqueous and methanolic extracts of Moringa oleifera have previously been shown to possess antihyperglycemic and antidiabetic activity, which has been attributed to their polyphenols content particularly phenolic acids, flavonoids and tannins [5]-[8]. We show in this study that Moringa functional tea equally possesses these benefits and is a more convenient form of consumption of polyphenols from Moringa oleifera. Possible antihyperglycemic mechanisms for polyphenols include inhibition of $\alpha$-amylase, $\alpha$ glucosidase and intestinal glucose absorption by sodium-dependent glucose transporters at intestinal level [3] [22]-[25]; improving glucose uptake by peripheral tissues, suppression of gluconeogenesis and stimulation of insulin secretion in circulation [3] [23] [26]. The differences in blood glucose changes observed with high and low doses in humans and rat models may indicate that different mechanisms are at work and needs further investigations.

Moringa tea exhibited strong antioxidant potential which may be working in synergy with glucose inhibition by polyphenols to booster its antihyperglycemic effect. Significant increases in insulin secretion and decrease in blood glucose following glucose loading have been reported in rats previously fed high antioxidant $\alpha$-tocopherol diets compared to rats whose diet was deficient in $\alpha$-tocopherol [27]. The authors suggested that $\alpha$-tocopherol reduced oxidative stress and thus increased insulin secretion which led to a reduction in blood glucose.

\section{Conclusion}

Tea being a widely consumed beverage, this study demonstrates that Moringa oleifera functional tea has antihyperglycemic activity in rat models and in human subjects, and may be a convenient form for the consumption of Moringa polyphenols. In addition, Moringa tea has strong antioxidant potential which may boost its antihyperglycemic effect. Moringa oleifera tea could thus be beneficial as a functional food in regulating blood glucose levels and preventing further complications of diabetes. Further studies are needed to evaluate its effect in diabetic conditions and to better understand its mode of action.

\section{Acknowledgements}

The authors express their gratitude to all the students who participated voluntarily in the study.

\section{References}

[1] Whitney, E. and Sharon, R.R. (2011) Understanding Nutrition. 12th Edition, Wadsworth, Belmont, 620-625. 
[2] International Diabetes Federation (2015) IDF Diabetes Atlas. 7th Edition. http://www.idf.org/

[3] Hanhineva, K., Törrönen, R., Bondia-Pons, I., Pekkinen, J., Kolehmainen, M., Mykkänen, H. and Poutanen, K. (2010) Impact of Dietary Polyphenols on Carbohydrate Metabolism. International Journal of Molecular Sciences, 11, 1365-1402. http://dx.doi.org/10.3390/ijms11041365

[4] Bahadoran, Z., Mirmiran, P. and Azizi, F. (2013) Dietary Polyphenols as Potential Nutraceuticals in Management of Diabetes: A Review. Journal of Diabetes \& Metabolic Disorders, 12, 43. http://dx.doi.org/10.1186/2251-6581-12-43

[5] Soliman, G.Z.A. (2013) Anti-Diabetic Activity of Dried Moringa oleifera Leaves in Normal and Streptozotocin (Stz)-Induced Diabetic Male Rats. Indian Journal of Applied Research, 3, 2249-2555.

[6] El-Desouki, N., Ibrahim, B.M.A., Hegazi, M.M.A. and El-Aama M.S.I. (2015) Moringa oleifera Leaf Extract Ameliorates Glucose, Insulin and Pancreatic Beta Cells Disorder in Alloxan-Induced Diabetic Rats. Research Journal of Pharmaceutical Biological and Chemical Sciences, 6, 642-654.

[7] Edoga, C.O., Njoku, O.O., Amadi, E.N. and Okeke, J.J. (2013) Blood Sugar Lowering Effect of Moringa oleifera Lam in Albino Rats. International Journal of Science and Technology, 3, 88-90.

[8] Luangpiom, A., Kourjampa, W. and Junaimaung, T. (2013) Anti-Hyperglycemic Properties of Moringa oleifera Lam. Aqueous Leaf Extract in Normal and Mildly Diabetic Mice. British Journal of Pharmacology and Toxicology, 4, 106-109.

[9] Matsui, T., Ebuchi, S., Kobayashi, M., Fukui, K., Sugita, K., Terahara, N. and Matsumoto, K. (2002) Anti-Hyperglycemic Effect of Diacylated Anthocyanin Derived from Ipomoea Batatas Cultivar Ayamurasaki Can Be Achieved through the Alpha-Glucosidase Inhibitory Action. Journal of Agricultural and Food Chemistry, 50, 7244-7248. http://dx.doi.org/10.1021/jf025913m

[10] Paliwal, R., Veena, S. and Pracheta (2011) A Review on Horse Radish Tree (Moringa oleifera): A Multipurpose Tree with High Economic and Commercial Importance. Asian Journal of Biotechnology, 3, 317-328. http://dx.doi.org/10.3923/ajbkr.2011.317.328

[11] Saa, R.W. (2012) Production et évaluation in vivo des propriétés antihyperglycémiantes d'une tisane à base de poudre de feuilles de Moringa oleifera LAM. (Production and In Vivo Evaluation of the Antihyperglycemic Properties of a Herbal Tea from Moringa oleifera Leaf Powder). MSc. Thesis, Department of Food Science and Nutrition, University of Ngaoundere, Ngaoundere, $99 \mathrm{p}$.

[12] Makkar, H.P.S., Siddhuraju, P. and Becker, K. (2007) Plant Secondary Metabolites. Humana Press, Totowa. http://dx.doi.org/10.1007/978-1-59745-425-4

[13] Adom, K., Sorrells, M. and Liu, R. (2003) Phytochemical Profiles and Antioxidant Activity of Wheat Varieties. Journal of Agricultural and Food Chemistry, 51, 7825-7834. http://dx.doi.org/10.1021/jf0304041

[14] Chew, K.K., Ng, S.Y., Thoo, Y.Y., Khoo, M.Z., Wan, A.W.M. and Ho, C.W. (2011) Effect of Ethanol Concentration, Extraction Time and Extraction Temperature on the Recovery of Phenolic Compounds and Antioxidant Capacity of Centella asiatica Extracts. International Food Research Journal, 18, 571-578.

[15] Brand-Williams, W., Cuvelier, M.E. and Berset, C. (1995) Use of a Free Radical Method to Evaluate Antioxidant Activity. Lebensmittel-Wissenschaft \& Technologie, 28, 25-30. http://dx.doi.org/10.1016/S0023-6438(95)80008-5 
[16] Yen, G.C. and Chen, H.Y. (1995) Antioxidant Activity of Various Tea Extracts in Relation to Their Antimutagenicity. Journal of Agricultural and Food Chemistry, 43, 27-32. http://dx.doi.org/10.1021/jf00049a007

[17] Suter, M. and Richter, C. (2000) Anti and Pro-Oxidative Properties of PADMA 28, a Tibetan Herbal Formulation. Redox Report, 5, 17-22.

http://dx.doi.org/10.1179/rer.2000.5.1.17

[18] Kebieche, M. (2009) Activité biochimique des extraits flavonoïdiques de la plante Ranunculus repens L: Effet sur le diabète expérimental et l'hépatotoxicité induite par l'Epirubicine. Biochimie, These deDoctorat, UniversitéMentouri Constantine, 143 p.

[19] Fischer, E. and Stein, E.A. (1961) DNS Colorimetric Determination of Available Carbohydrates in Foods. Biochemical Preparation, 8, 30-37.

[20] Knapp, R.G. and Miller, M.C. (1992) Clinical Epidemiology and Biostatistics. The National medical Series for Independent Study, Harwal Publishing Company, Malverin, 275-292.

[21] Ijeomah, A.U., Ugwuona, F.U. and Abdullahi1, H. (2012) Phytochemical Composition and Antioxidant Properties of Hibiscus sabdariffa and Moringa oleifera. Nigerian Journal of Agriculture, Food and Environment, 8, 10-16.

[22] Scalbert, A., Manach, C., Morand, C., Rémésy, C. and Jiménez, L. (2005) Dietary Polyphenols and the Prevention of Diseases. Critical Reviews in Food Science and Nutrition, 45, 287-306. http://dx.doi.org/10.1080/1040869059096

[23] Kim, Y., Keogh, J.B. and Clifton, P.M. (2016) Polyphenols and Glycemic Control. $\mathrm{Nu}$ trients, 8, 17. http://dx.doi.org/10.3390/nu8010017

[24] Jimoh, A., Tanko, Y. and Mohammed, A. (2013) Modulatory Role of Methanolic Leaf Extract of Cissus cornifolia on Blood Glucose Levels of Normoglycemic Wistar Rats. European Journal of Experimental Biology, 3, 22-27.

[25] Kwon, O., Eck, P., Chen, S., Corpe, C.P., Lee, J.-H., Kruhlak, M. and Levine, M. (2007) Inhibition of the Intestinal Glucose Transporter GLUT2 by Flavonoids. FASEB Journal, 21, 366-377. http://dx.doi.org/10.1096/fj.06-6620com

[26] Jaiswal, D., KumarRai, P., Kumar, A., Mehta, S. and Watal, G. (2009) Effect of Moringa oleifera Lam. Leaves Aqueous Extract Therapy on Hyperglycemic Rats. Journal of Ethnopharmacology, 123, 392-396. http://dx.doi.org/10.1016/j.jep.2009.03.036

[27] Iharaa, Y., Yamadaa, Y., Toyokunib, S., Miyawakia, K., Bana, N., Adachia, T., Kuroea, A., Iwakuraa, T., Kubotaa, A., Hiaib, H. and Seinoa, Y. (2000) Antioxidant $\alpha$-Tocopherol Ameliorates Glycemic Control of GK Rats, a Model of Type 2 Diabetes. Federation of European Biochemical Societies Letters, 473, 24-26. http://dx.doi.org/10.1016/S0014-5793(00)01489-7 
Submit or recommend next manuscript to SCIRP and we will provide best service for you:

Accepting pre-submission inquiries through Email, Facebook, LinkedIn, Twitter, etc. A wide selection of journals (inclusive of 9 subjects, more than 200 journals)

Providing 24-hour high-quality service

User-friendly online submission system

Fair and swift peer-review system

Efficient typesetting and proofreading procedure

Display of the result of downloads and visits, as well as the number of cited articles

Maximum dissemination of your research work

Submit your manuscript at: http://papersubmission.scirp.org/

Or contact fns@scirp.org 